\title{
Evolution of the wall-crystal interface as witness of the heterogeneous nucleation and growth of Naica's giant crystals
}

\author{
M. E. Montero-Cabrera' ${ }^{1}$, B. Pérez-Cázares ${ }^{2}$, M. E. Fuentes-Montero ${ }^{2}$, L. E. Fuentes-Cobas ${ }^{1}$, I. Castillo-Sandoval ${ }^{1}$, \\ I.J.A. Carreño-Márquez ${ }^{3}$, H. E. Esparza-Ponce ${ }^{1}$, D. Eichert ${ }^{4}$, R. Loredo-Portales ${ }^{5}$, L. Pardo ${ }^{6}$
}

${ }^{1}$ Centro de Investigación en Materiales Avanzados (CIMAV), Ave. Miguel de Cervantes 120, Complejo Industrial, C.P. 31136, Chihuahua, Chih. México, ${ }^{2}$ Universidad Autónoma de Chihuahua, Campus Universitario \#2, Circuito Universitario, C.P. 31125 , Chihuahua, Chih. México, ${ }^{3}$ Universidad La Salle Chihuahua. Coordinación de Ingeniería. Prolongación Lomas de Majalca 11201, Labor de Terrazas, C.P. 31020, Chihuahua, Chihuahua, Mexico ${ }^{4}$ Elettra Sincrotrone-Trieste, S.C.p.A., AREA Science Park, 34149 Basovizza (Trieste) Italy, ${ }^{5}$ CONACYT-Universidad Nacional Autónoma de México, Av. Luis D. Colosio M. esq. Madrid s/n, C.P. 83000, Hermosillo, Sonora, México, 'Instituto de Ciencia de Materiales de Madrid, Madrid, Spain

elena.montero@cimav.edu.mx

Naica's giant crystals caves have astonished scientists since their discovery in 2000. Their gypsum crystals have been the subject of extensive studies and reports, both on scientific aspects and general cultural news. This work reports a detailed investigation of the wall-crystal interface of a blocky type crystal pulled off the "Cueva de los Cristales" wall. At the interface, the zones that probably correspond to the nucleation and growth of the blocky were identified. Representative samples were extracted at different depths of the wall-crystal junction and studied by ICP-OES, light and electron microscopies, XRD, and synchrotron-based $\mu$-XRF and $\mu$ XANES methods. The interface layer, of an average thickness of about 30 to $60 \mu \mathrm{m}$, contains various crystalline and amorphous aggregates with diameters ranging from 1 to $30 \mu \mathrm{m}$. Calcite, silica, goethite, as well as several $\mathrm{Pb}, \mathrm{Mn}, \mathrm{Cu}$, and $\mathrm{Zn}$ aggregates, have been identified as main components (Figure 1).

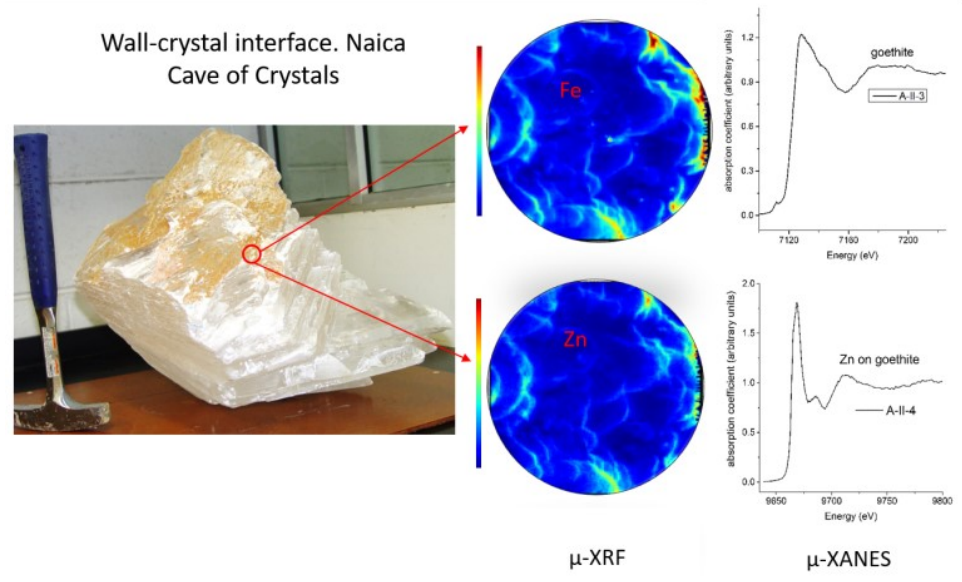

Figure 1.The wall-crystal interface of Cueva de los Cristales, with Fe and $\mathrm{Zn} \mu$-XRF and $\mu$-XANES obtained from the sample.

The study of the shape and composition of these mineral aggregates, as well as the morphology of the wall-crystal interface, allowed deducing their transformation and role in the crystal nucleation and growth. It has been concluded [1] that the nucleation and growth of the Naica giant crystals have occurred under conditions of a slightly supersaturated solution, almost in equilibrium, and stable over a long time. In addition, considering the non-classical theory of crystal nucleation [2] and the results presented here, we can formulate that the heterogeneous nucleation of the giant Naica crystals was initiated with the adsorption of nanocrystalline monomers. These clusters formed in the solution were successively physi- and chemisorbed on the cave walls and on the crystal surface, assembling the crystalline planes during the crystal growth.

The CONACYT (México), Projects 183706, 257912 and 270738, and Project MINECO(Spain) MAT2017-86168-R are acknowledged.

[1] Otalora, F. \& Garcia-Ruiz, J. (2014). Chem. Soc. Rev. 43, 2013-2026.

[2] Van Driessche, A. E. S., Stawski, T. M. \& Kellermeier, M. (2019). Chem. Geol. 530, 119274.

Keywords: Naica; Cueva de los Cristales; SEM-EDS; $\mu$-XRF and $\mu$-XANES; heterogeneous nucleation 